\title{
Studies of Defence Mechanisms and Inflammatory Reactions in the Bovine Teat using a New Experimental Method
}

Bovine intramammary infections are usually caused by microorganisms entering through the teat canal. The teat canal normally acts as a mechanical and physiological barrier preventing bacteria from entering the teat cistern. This barrier can be broken, e.g. if the teat end is damaged, making it possible for bacteria to invade the teat cistern. If an infection is established inflammatory reactions will occur in the udder.

Defence factors in mammary secretions have been intensively studied for the last 2 decades. However, whether those factors originate in the gland or in the teat is not known. One of the most important defence factors, the leucocytes, is present in mammary secretions and in gland tissue but also in teat tissue, especially in the area of Fürstenberg's rosette (Nickerson \& Pankey 1983). Lymphoid cells were the dominating cell type in teat tissue from uninfected quarters while the number of cells of all types, especially the polymorphonuclear neutrophils (PMNs), was increased in teat tissue from infected quarters (Nickerson \& Pankey 1983). A marked concentration of PMNs passing the epithelial lining was noted in the area of Fürstenberg's rosette (Nickerson \& Pankey 1984). Immunisation experiments gave further proofs of strong immunological ability in the teat end (Nickerson \& Nonnecke 1986).

These findings suggest a release of defence factors through the teat wall into the teat cistern. Studies to elucidate this are needed but suitable methods have so far not been available. A surgical method which separates the teat cistern from the udder cistern without damaging the circulation of the teat has now been developed, providing a method for studying the inflammatory reactions and defence mechanisms in the teat. This also allows comparisons between reactions in the teat and in an intact udder quarter in the same cow to be carried out.

Non-lactating, clinically healthy cows without earlier records of udder diseases were used. Samples were collected by flushing of the teat cistern with $4 \mathrm{ml}$ sterile physiological saline (SPS) before and 6, 24, 48, 72 and $96 \mathrm{~h}$ after infusion with SPS or endotoxin. Infusion with $1 \mathrm{ml}$ SPS into the teat cistern did not produce any significant somatic cell count (SCC) changes, while infusion with 5 $\mu \mathrm{g}$ Salmonella endotoxin in $1 \mathrm{ml}$ SPS resulted in a sharp increase in SCC within $6 \mathrm{~h}$ of the infusion, as shown in Fig. 1. The cell count was still elevated $24 \mathrm{~h}$ post infusion (p.i.) but had decreased to pre-infusion levels 48 h p.i.

Besides somatic cell count, other parameters of interest are also studied, e.g. differential cell count, immunoglobulins, bovine serum albumin and $\mathrm{N}$-acetyl- $\beta$-D-Glucosaminidase. The proteolytic enzyme plasmin and the antibacterial proteins lysozyme and lactoferrin are also analysed. Finally, histological studies to further elucidate the reactions of the teat are carried out.

The described method could prove to be of 

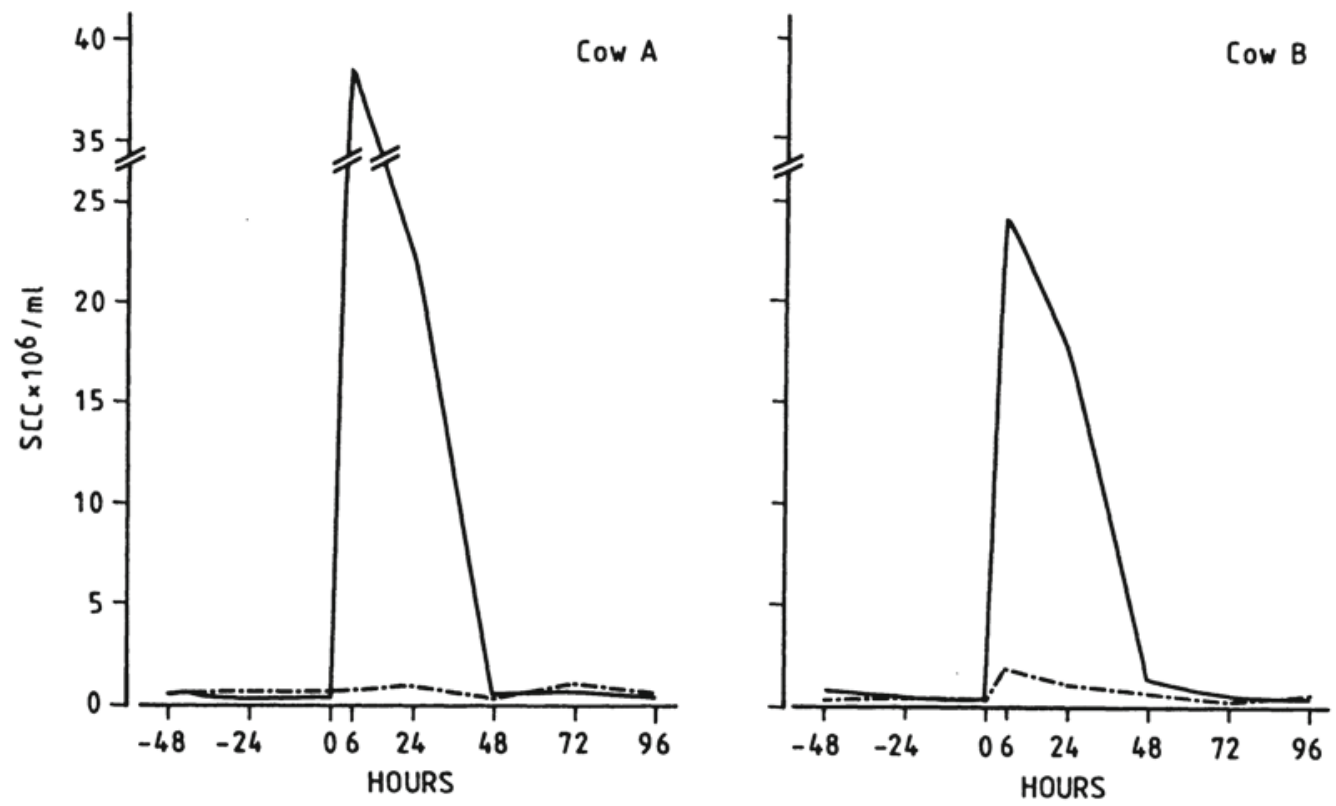

Figure 1. Somatic cell count (SCC) in cows A and B before and after infusion of one teat with $5 \mu \mathrm{g} \mathrm{Sal-}$ monella endotoxin in $1 \mathrm{ml}$ sterile physiological saline $(-)$ and one teat with $1 \mathrm{ml}$ physiological saline $(--)$ at $0 \mathrm{~h}$.

great importance, by making it possible to learn more about the inflammatory reactions and defence mechanisms in the teat and the possibility to support and enhance those mechanisms.

\section{Acknowledgements}

The work supported by the Swedish Council for Forestry and Agricultural Research.

Karin Persson, Olof Holmberg and Göran Åström,

Departments of Obstetrics and Gynaecology and of Veterinary Microbiology,

Section of Clinical Microbiology;

College of Veterinary Medicine,

Swedish University of Agricultural Sciences, Uppsala, Sweden.

(Received December 9, 1988).

\section{References}

Nickerson SC, Pankey JW: Cytological observations of the bovine teat end. Amer. J. vet. Res. 1983, 44, 1433-1441.

Nickerson SC, Pankey JW: Neutrophil migration through teat end tissues of bovine mammary quarters experimentally challenged with Staphyloccus aureus. J. Dairy Sci. 1984, 67, 826834.

Nickerson SC, Nonnecke BJ: Tuberculin elicited immune response in the lactating bovine mammary gland vaccinated intramammarily with Mycobacterium bovis. Vet. Immunol. Immunopathol. 1986, 13, 39-50.

Reprints may be requested from: K. Persson, Department of Obstetrics and Gynaecology, College of Veterinary Medicine, Swedish University of Agricultural Sciences, P. O. Box 7039, S-750 07 Uppsala, Sweden. 